\title{
Principais correntes de estudo da criatividade e suas relações com o esporte
}

\section{RESUMO}

Este trabalho tem como objetivo apresentar os : diferentes pensamentos e visões sobre : criatividade, bem como relacioná-los com o : esporte de uma forma geral. A visão mística, : pragmática, cognitiva, psicométrica e social da : criatividade, bem como seus principais conceitos : e linhas de pensamentos, são apresentados de : forma sistemática e sucinta ao relacioná-los : com o fenômeno esportivo. Apresentam-se ainda : novas perspectivas sobre os paradigmas que : envolvem o estudo da criatividade na atualidade. : UNITERMOS: criatividade, jogos coletivos, : comportamento criativo, processos cognitivos, personalidade.

\section{ABSTRACT}

This study aims to present the different approaches : about creativity and its correlations with sport. The " mystical, pragmatic, psychodynamic, cognitive, : psychometric, and social view of creativity as well : as your main concepts and visions are presented: systematically aiming to correlate them with the: sport phenomenon. The new trends about the: paradigms that involve the present study of creativity : are approached also.

UNITERMS: creativity, collective games, creative : behavior, cognitive process, personality.

\author{
Dietmar Martin Samulski ${ }^{1}$ \\ Franco Noce ${ }^{2}$ \\ Varley Teoldo da Costa
}

\section{1-INTRODUÇÃO}

Segundo STERNBERG \& LUBART (1999) a criatividade

é um assunto abrangente, complexo e é importante em todas as esferas da vida humana para o domínio de tarefas. Estas esferas podem se dar no plano individual ou social.

No nível individual, a criatividade é relevante quando a pessoa está resolvendo problemas no trabalho e na vida diária. No nível social, a criatividade pode levar para novos achados científicos, novos movimentos em arte, novas invenções tecnológicas e novos programas sociais. A importância econômica da criatividade está clara porque novos produtos e serviços criam trabalhos. Além disso, indivíduos, organizações e sociedade devem adaptar-se aos recursos existentes e às variáveis de demandas de tarefas para permanecer competindo no mercado (STERNBERG \& LUBART, 1999)

No esporte não poderia ser diferente, a criatividade se manifesta no sentido de algo inesperado, inovativo ou fora dos padrões normais de ação que o atleta consegue realizar na modalidade em que ele está inserido.

Dentro do esporte, principalmente nos jogos coletivos, como por exemplo voleibol, futsal, basquete, handebol e futebol de campo, é sonho de qualquer clube e técnico poder contar em sua equipe com jogadores criativos e capazes de solucionar problemas de ordem técnico-tática e de criar novas jogadas.

Jogadores criativos sem dúvida, na maioria das vezes, são o diferencial entre um resultado positivo e uma derrota. Qual clube de futebol não gostaria de contar com um Romário? Qual equipe de basquete não queria ter um Michael Jordan dentro de seu elenco? E no 


\begin{abstract}
futsal mundial, que equipe dispensaria os serviços de um Manoel Tobias?

Para esses atletas não faltam elogios e atributos, como serem jogadores criativos, fora de série, craques, gênios, enfim, uma série de adjetivos que tentam enaltecer o diferencial que os mesmos provocam quando estão competindo dentro de suas modalidades.

Porém, o que se nota é que esse tipo de atleta está cada vez mais escasso e precioso na atual conjuntura do esporte mundial, devido a uma série de variáveis dentre elas a constante evolução profissional que vem sofrendo os esportes de um modo geral.
\end{abstract}

Segundo HAMSEN \& SAMULSKI (1999) a criatividade é um objeto de estudo que desperta muita curiosidade para os cientistas que

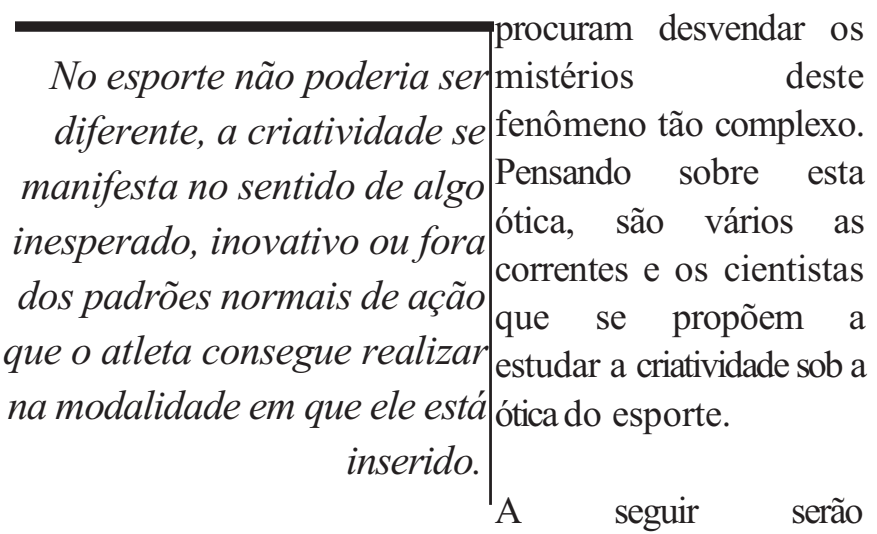
apresentadas e discutidas as principais correntes de criatividade e como elas se manifestam dentro do esporte de uma forma geral.

\section{2- PRINCIPAIS CORRENTES DO ESTUDO DE CRIATIVIDADE}

\section{1- Corrente mística:}

Segundo STERNBERG \& LUBART (1999) as origens do estudo de criatividade foram baseadas na tradição do misticismo e espiritismo, o qual parecem estar distanciadas do espírito científico. Para estes autores, a criatividade sempre que tem sido investigada faz associações com as crenças místicas. Os mais antigos relatos de criatividade foram baseados na intervenção divina. A pessoa criativa foi vista como um vaso vazio que um divino existente encheria com inspiração. $\mathrm{O}$ indivíduo depois exteriorizaria as idéias inspiradas, formando um produto de outro mundo.

Nesta linha, Platão discutiu que um poeta é capaz de criar somente aquilo que a sua "mitologia" mandar e até hoje as pessoas, algumas vezes, recorrem à suas próprias "mitologias" como fonte de inspiração. $\mathrm{Na}$ visão de Platão, uma pessoa pode se inspirar para criar sons de coral, poemas épicos, etc. (ROTHENBERG \& HAUSMAN, 1976).

No esporte é comum observamos em entrevistas com atletas criativos que eles atribuem suas qualidades a um dom divino ou uma graça que lhes foi concedida por um ser superior.

Em entrevistas com jogadores do futebol brasileiro, considerados criativos, observa-se que eles definem sua criatividade no esporte como um dom divino que eles receberam no seu nascimento e que lhes proporciona realizar jogadas tão geniais (HAMSEN \& SAMULSKI, 1999).

\section{2- Corrente pragmática:}

A corrente pragmática é uma das várias linhas de estudo da criatividade e sua principal característica esta na utilização métodos e técnicas que estimulam as pessoas a desenvolverem ações criativas dentro de um determinado ambiente (ver DE BONO, 1992).

Pesquisadores inseridos nesta corrente (DE BONO, 1971,1985,1992; OSBORN, 1953) tem se preocupado primeiramente com o desenvolvimento da criatividade e posteriormente com o entendimento da mesma. A preocupação de DE BONO não é com a teoria, mas com a prática.

Um dos métodos utilizados por DE BONO (1992) é o "chapéu de pensamentos", no qual cada indivíduo é estimulado a ampliar seu pensamento sobre determinado assunto, para ser capaz de interpretar uma situação sob diferentes óticas.

OSBORN (1953) baseou seus experimentos em agências de publicidade, desenvolvendo a técnica de "tempestade cerebral" (brain-storming) para encorajar pessoas a resolver problemas criativamente. A técnica 
busca várias soluções possíveis dentro de uma " atmosfera que é construída sem crítica e com " desinibição.

Segundo STERNBERG \& LUBART (1999) técnicas " como "a tempestade cerebral de idéias" ou o "chapéu . de pensamentos" que incentivam pessoas ligadas a : determinadas atividades a aflorarem o seu potencial " criativo estão sendo constantemente utilizadas dentro do universo empresarial, contudo a maioria destes instrumentos ainda carecem de validação científica " para que se verifique a sua eficiência prática.

STERNBERG \& LUBART (1999) criticam ainda os estudos dentro da corrente pragmática que oferecem : instrumentos para o desenvolvimento da criatividade. Segundo estes autores a maioria destes instrumentos utilizados não foram testados e validados cientificamente.

Concordamos com STERNBERG \& LUBART (1999) : quando os mesmos sugerem que a criação de " instrumentos ou técnicas precisam passar por um : rigoroso tratamento científico de validação.

No esporte observa-se que as manifestações dessa " corrente acontecem quando os atletas são submetidos a determinadas dinâmicas e técnicas neurolingüísticas que fomentam seu potencial ou poderio criativo.

Às vésperas de jogos decisivos ou finais de : campeonato, é comum dirigentes e os próprios " treinadores de equipes buscarem profissionais ou " pessoas de sucesso que tenham uma boa oratória, : para ministrarem palestras para o seu grupo de atletas. Este tipo de atitude busca através de técnicas neurolingüísticas oferecer uma dose extra de motivação, confiança e de inspiração criativa para que " os atletas possam durante a partida apresentar níveis de rendimento superiores a sua habitual performance.

Sendo assim, esse tipo de intervenção no esporte, " nos oferece uma impressão de que, através de técnicas ministradas de forma esporádica, é possível otimizar o potencial criativo de um grupo de atletas. Desta forma o trabalho sistemático para o desenvolvimento da capacidade criativa, segundo HAMSEN \& SAMULSKI
(1999) fica relegado a segundo plano.

Entendemos que somente através de um trabalho cientificamente estruturado, com metas e perspectivas realistas, em um ambiente favorável que otimize o desenvolvimento do potencial criativo, é que poderemos obter resultados positivos.

\section{3- Corrente psicodinâmica:}

Segundo STERNBERG \& LUBART (1999), a corrente da psicodinâmica pode ser considerada a primeira e maior linha teórica do século XX para o estudo da criatividade.

Um dos grandes problemas enfrentados por esta corrente é a forma como as pesquisas na área de criatividade são conduzidas. Na maioria das vezes, as pesquisas se concentram em estudos de casos de pessoas que se destacaram e são considerados gênios em suas áreas (LUBART 1990, WEISBERG 1993).

Avaliações estatísticas ou finais de campeonato, é demonstram que a comum dirigentes e os próprios c o r r e $\mathrm{n}$ t e treinadores de equipes psicodinâmica da buscarem profissionais ou criatividade depende qu a s e que pessoas de sucesso que tenham exclusivamente de uma boa oratória, para estudos de caso de ministrarem palestras para o criadores eminentes seu grupo de atletas. como os de Leonardo da Vinci, Freud e Picasso que são utilizados para sustentar esta linha de raciocínio na qual o subconsciente atua no processo de desenvolvimento da criatividade (MADURO 1976).

Esta metodologia tem sido criticada, segundo WEISBERG (1993), em virtude da dificuldade em se medir as construções teóricas propostas (assim como o pensamento do processo primário) e a quantidade de seleções e interpretações que podem ocorrer nos estudos de caso.

As principais críticas, que este delineamento sofre, dizem respeito à dificuldade de se medir estas construções e avaliações teóricas. Embora não exista 
nada contra o método de estudo de casos, as linhas : da psicologia científica emergentes neste século: valorizam a capacidade de se controlar através de : diferentes métodos todo tipo de situação experimental.

Através de estudos científicos em diferentes áreas, : procura-se explicar o fenômeno da criatividade dentro : da corrente psicodinâmica. Baseado na idéia que a : criatividade surgiu da tensão entre realidade consciente : e uma viagem inconsciente, Freud (1908,1959), citado : por STERNBERG \& LUBART (1999), propôs que : escritores e artistas produziam seus trabalhos criativos : como uma forma de expressar seus desejos: inconscientes de uma maneira publicamente aceitável. : De acordo com Vermon (1970), citado por STERNBERG \& LUBART (1999), elementos : como força interior, riqueza, fama, honra e amor são :

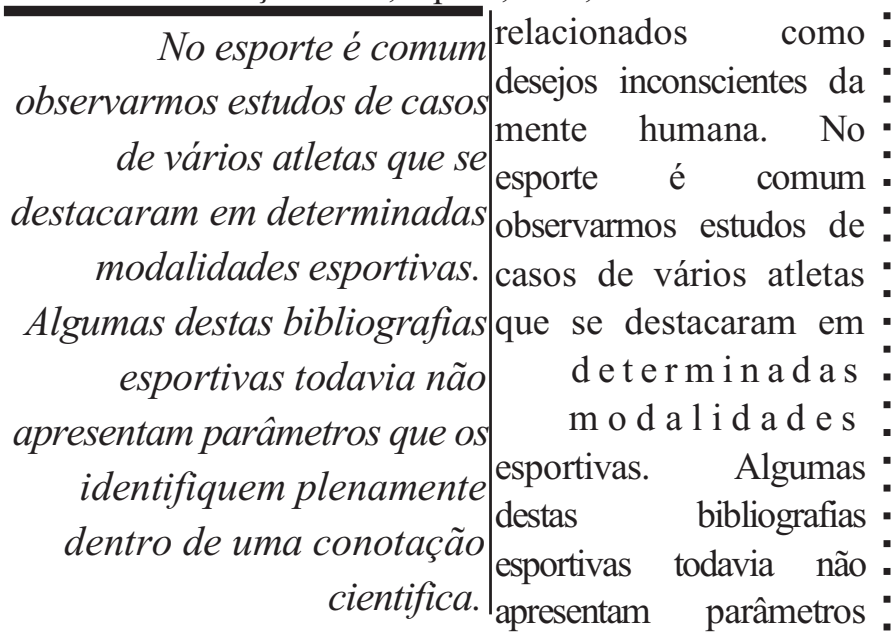
que os identifiquem plenamente dentro de uma conotação cientifica.

Pesquisadores como MORAES et al (1999) e SALMEIA : (1995) dentro de suas linhas de pesquisa através de : análise qualitativa no esporte acreditam que estudando : a história de vida de atletas como Pelé, Garrincha, : Michael Jordan, Oscar Schmidt e outros tornar-se-á : possível entender melhor os processos que os fizeram : destaque em suas modalidades. Outro fator levantado : é que através do entendimento e explicação das : diferentes variáveis intervenientes e que foram : influenciadas por estes "experts", será possível a : construção de modelos teóricos capazes de auxiliar : no entendimento do fenômeno da criatividade no esporte.

\section{4- Corrente cognitiva:}

Segundo STERNBERG \& LUBART (1999), a corrente cognitiva, como via de acesso para a criatividade, procura entender as representações mentais e o processo subordinado ao pensamento criativo. Temse estudado a cognição e a criatividade através de sujeitos humanos e simulações computadorizadas do pensamento criativo.

FINKE et al (1992) têm proposto o que eles chamam de "modelo Geneplore". De acordo com este modelo existem duas principais fases no processo do pensamento criativo. Uma fase generativa onde o indivíduo constrói representações mentais referente a estruturas prévias. Estas estruturas tem propriedades que promovem descobertas criativas. Uma outra fase denominada exploratória em que estas propriedades são usadas para propor idéias criativas.

O número de processos mentais que podem entrar dentro destas fases de invenções criativas incluem os processos de recordação, associação, síntese, transformação, transferência por analogia e redução categorial.

WEISBERG $(1986,1993)$ propõe que a criatividade envolve essencialmente processos cognitivos usuais produzindo produtos extraordinários.

Nos esportes de um modo geral e principalmente no voleibol, o produto criativo ou jogada criativa está muito relacionado à eficiência e precisão que um jogador possui para executar ou variar determinada técnica. (COSTA et al 2000:104).

Alguns técnicos, dentro do esporte, procuram aplicar métodos de treinamento relacionando os processos psíquicos para otimização de ações criativas de seus atletas. Para tanto utilizam situações práticas que envolvem processos mentais de recordação, associação, antecipação, transferência por analogia e tomada de decisão. Estas situações são oferecidas aos atletas na forma de exercícios que promovam estas habilidades. 
Os defensores da teoria de processamento de informações acreditam que com estímulos vivenciados : por estes atletas na prática é possível otimizar o : desenvolvimento do potencial criativo (ver SCHMIDT : 1993, MAGILL1984)

\section{5- Corrente da personalidade social:}

Paralelamente à via cognitiva, a personalidade social : é uma das vias para se compreender os processos : criativos. As características relacionadas a traços de personalidade, aspectos motivacionais e o: envolvimento sociocultural são variáveis importantes : dentro da personalidade social (STERNBERG \& LUBART1999).

Estudos de AMABILE (1983); GOUGH (1979) e : MACKINNON (1965) tem observado que certos traços: de personalidade normalmente caracterizam pessoas : criativas. Pessoas com traços de julgamento: independente, autoconfiança, atração pela : complexidade, orientação para o caráter estético : (beleza, plasticidade), periculosidade possuem uma : probabilidade maior de serem criativas.

STERNBERG \& LUBART (1999) citam estudos de Maslow nos quais os traços de audácia, coragem, : liberdade, espontaneidade, auto-aceitação podem : orientar a pessoa na percepção da totalidade de seu : potencial.

Estudos de AMABILE (1983), CRUTCHFIELD (1962) : e GOLLAN (1962) relacionam a motivação e a auto- : motivação com a criatividade. Segundo estes autores a motivação intrínseca serve para ordenar e fazer com : que haja o progresso em determinadas ações.

Trabalhando de forma paralela com a via cognitiva, : a corrente da personalidade social tem desenvolvido : estudos sobre a motivação intrínseca (AMABILE 1983; : HENNESSEY \& AMABILE, 1988). Segundo estes : autores é possível, através do treinamento : motivacional e outras técnicas, regular o nível de : motivação e observar os efeitos na performance : criativa de tarefas tais como escrever poemas e fazer colagens.

Pesquisas comparando diferentes culturas (LUBART,
1990) e estudos de casos antropológicos (MADURO, 1976; SILVER, 1981) demonstraram que existe uma grande variabilidade cultural na expressão da criatividade. As principais conclusões, segundo esses estudos, têm demonstrado que estas culturas diferem simplesmente na quantidade e no valor empreendido à criatividade.

No voleibol existem estudos interculturais sobre a criatividade, com atletas de diferentes países, que procuram investigar as relações culturais e os conceitos sobre criatividade de jogo criativo, produto criativo e o que são as características de um jogador criativo (ver ROTH, RAAB, GRECO, 1998).

\section{6- Corrente psicométrica:}

As pesquisas que envolvem a psicometria da criatividade têm recebido críticas positivas e negativas de vários cientistas da área. Destacaremos a seguir as principais colocações

destes estudiosos em relação ao estudo da criatividade através desta linha de pesquisa.

As criticas positivas da r e v o 1 u ç ã o psicométrica de mensuração de criatividade são que através delas foi possível preparar um resumo de idéias que tornaram sua utilização mais fácil de ser administrada. Foi possível também a criação de "scores" que permitem a taxação de vários esquemas e estruturas (ver ROTH, RAAB, GRECO 1998).

Alguns autores, dentre eles STERNBERG(1986), vêem a utilização da psicometria dentro dos estudos de criatividade como algo extremamente negativo. Eles afirmam que avaliação escrita é trivial e não retratam a realidade de algumas situações como, por exemplo, nos jogos esportivos coletivos.

AMABILE (1983) afirma que os critérios de "score", flexibilidade, fluência, originalidade e elaboração são falhos e passíveis de erros por parte de seus organizadores. 
STERNBERG \& LUBART (1996) rejeitam a criação de níveis para se medir a criatividade, sugerindo que este componente não pode e não deve ser mensurado através de dados quantitativos.

Entendemos que a corrente psicométrica vem de encontro no sentido de ajudar a solucionar os problemas relacionados a atletas criativos nos diferentes esportes. GUILFORD (1966), um dos grandes pesquisadores da área da criatividade, propõe que este tema deve ser estudado com toda a sua subjetividade e através da utilização de vias psicométricas.

Através de testes que envolvem tarefas escritas, sugeridas por Guilford, foi possível escalonar indivíduos dentro de níveis de criatividade. GUILFORD (1966) identificou em uma grande variedade de estudos, através de processos estatísticos de a nális e multifatorial, mais de 120

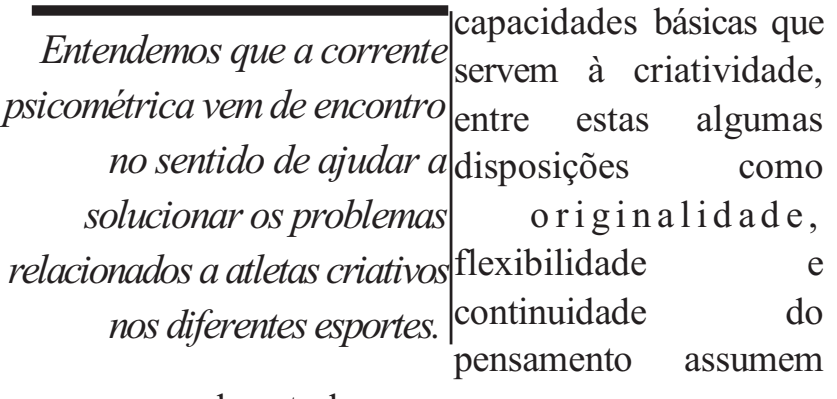
um papel central.

TORRANCE (1974), subsidiado pelos trabalhos de Guilford desenvolveu o Teste de Pensamento Criativo de Torrance. O Teste de Torrance é baseado em tarefas simples (verbal/figurai) que envolvem pensamento divergente mais habilidades para solucionar problemas.

O teste de Torrance é composto por quatro variáveis fundamentais:

- Fluência ou continuidade: refere-se ao número total de respostas relevantes à sua adequação

- Flexibilidade: neste item é observado o número de diferentes categorias de respostas relevantes.

- Originalidade: destaca-se particularmente as novidades, os aspectos pouco comuns, a força da inovação, como também a exclusividade com que se carateriza a ação.

- Elaboração: neste item observa-se a quantidade e a qualidade de detalhes da resposta.

Alguns subtestes são incluídos dentro da bateria de avaliação de Torrance visando uma maior confiabilidade dos resultados avaliados anteriormente. Os subtestes são divididos em 4 categorias:

- Questões escritas: o testando escreve todas as questões que ele pode pensar sobre determinada cena.

- Desenvolvimento do produto: o testando listará outras alternativas de solucionar aquela situação de jogo que lhe foi apresentada.

- Uso pouco comum: o testando lista usos interessantes e pouco comuns de uma determinada ação.

- Circunferências/círculos: o testando através de associações espalha círculos vazios de diferentes desenhos e nomeia-os.

Estudo de GRECO (1995) avaliando o comportamento tático em Handebol, afirmam que a estrutura do rendimento nos jogos esportivos coletivos esta baseada na interação de seus componentes, sendo que a ênfase destes na competição é dada pelas capacidades psíquicas (regulação das ações), pelas capacidades técnicas (coordenação motora) e pelas capacidades táticas (elaboração de resposta, e tomada de decisão) em função da própria situação de jogo.

GRECO et al (1998) nos Jogos da Juventude de 1997 avaliaram o nível de conhecimento tático nas modalidades futsal, voleibol e handebol de 614 jovens atletas do sexo masculino e feminino na faixa etária de 14 a 17 anos de idade.

Os procedimentos utilizados por GRECO et al (1998:83) constam de situações típicas de jogo nas modalidades futsal, handebol e voleibol apresentadas em formas de diagramas, fotos, slides e vídeo; onde o atleta deve escolher uma alternativa de solução ou resposta ao problema e posteriormente justifica-la.

As justificativas eram analisadas dentro dos parâmetros fluência ou continuidade, flexibilidade, originalidade e elaboração, ficando o produto criativo dependente 
da eficiência da ação.(ver GRECO 1998).

PAULA (2000) desenvolveu, construiu e validou um : teste para avaliar a capacidade de decisão tática e o : conhecimento declarativo em situações de ataque no : voleibol, analisando a forma como este instrumento foi : construído observamos características redundantes de : traços da corrente psicométrica de estudo da : criatividade.

Conforme considerações feitas pelos estudos de : GRECO (1995), ROTH et al (1998), PAULA (2000), : verificamos que o conhecimento tático depende de : uma série de processos cognitivos envolvendo por : exemplo parâmetros relacionados ao pensamento : criativo, a inteligência de jogo e outros aspectos: cognitivos como a tomada de decisão, pensamento : divergente e convergente.

Após estas análises observamos que a corrente psicométrica de estudo da criatividade possui uma : relação forte com o esporte, sendo que a cada dia : surgem novos trabalhos científicos que tentam avaliar : parâmetros como (criatividade, inteligência de jogo, : tomada de decisão) dentro das modalidades : esportivas.

\section{3- CONCLUSÕES E CONSIDERAÇÕES FINAIS:}

Após uma breve e sucinta descrição das principais " correntes de estudo da criatividade, bem como suas : correlações com o esporte, é de nosso interesse e : objetivo sensibilizar os pesquisadores da área para a : necessidade de se promover mais estudos e discussões : que ajudem a elucidar as relações entre a criatividade : e o esporte.

A maioria das pesquisas em criatividade são : unidimensionais, negligenciando vários aspectos. Esta : tendência tem feito com que as descobertas das : pesquisas sejam distorcidas, já que somente através de uma única corrente não é possível explicar um fenômeno complexo, muito menos relacioná-lo com : o esporte.

Precisamos compreender que somente através de ações integradas entre diferentes campos do conhecimento será possível construir um arcabouço de respostas que permitam responder as principais perguntas envolvendo a criatividade e o esporte em suas diferentes concepções (recreacional, educacional, adaptado e de rendimento)

Pesquisas recentes apontam para uma nova perspectiva através de estudos multidimensionais que procuram avançar em diferentes esferas do potencial criativo do indivíduo (CSIKSZENTMIHALYI, 1988a; 1988b; FELDHUSEN \& GOH, 1995; FELDMAN, 1990; GARDNER，1988，1993; SIMONTON，1988; STERNBERG \& LUBART, 1996).

\section{O caminho proposto por CSIKZIENTMIHALYI(1988a,}

1988b, 1990) é atualmente mais interativo porque enfatiza a necessidade

de considerar o

indivíduo, o domínio

e o campo como um

dinâmico grupo de

influências mútuas.

Dentro da visão do

esporte esta teoria é

perfeitamente

compreensível, pois

através das diferentes

correntes e

concepções sobre

criatividade é possível

compreender como o

atleta criativo

A maioria das pesquisas em

criatividade são

unidimensionais,

negligenciando vários aspectos.

Esta tendência tem feito com

que as descobertas das

pesquisas sejam distorcidas, já

que somente através de uma

única corrente não é possivel

explicar um fenômeno

complexo, muito menos

relacioná-lo com o esporte. (indivíduo), que

possui determinadas características (domínio) de ordem técnica, tática, física e psicológica que o difere de outros atletas, se enquadra dentro uma determinada modalidade esportiva (campo).

Através da confluência de várias teorias poder-se-á estabelecer um caminho mais promissor para o desenvolvimento de um modelo dimensional, mais explícito do processo criativo, que envolva as particularidades específicas de cada modalidade esportiva.

Após esta breve abordagem e mediante uma extensa revisão bibliográfica na área concluí-se que: 
- Não existem comprovações que permitam afirmar : cientificamente que a criatividade pode ser: desenvolvida nos atletas de uma forma geral.

- Sabe-se muito pouco sobre a treinabilidade de : elementos relacionados ao desenvolvimento da: criatividade e do produto criativo, ou seja, ainda : estamos caminhando em fundamentações teóricas : que não conseguem explicar o fenômeno da : criatividade em todas as suas dimensões no esporte. - Poucas pesquisas estão voltadas para o estudo da : criatividade. Somente $0,5 \%$ das publicações, no " período de 1975 a 1994, na área de psicologia são : voltados para o estudo da criatividade (STERNBERG : \& LUBÁRT, 1999:3). Com base nesta afirmação, : observa-se que poucos são os pesquisadores que se : atrevem, através de trabalhos científicos, oferecer : caminhos e subsídios que elucidem as relações entre : o esporte e a criatividade.

- É pequeno o corpo de conhecimentos, concepções, : vocabulários tecnologias e técnicas de mensuração : teórica e prática que permitam estabelecer relações : seguras e confiáveis, do ponto de vista científico, entre : a criatividade e o esporte.

Embora estejamos longe de uma explicação adequada : para o avanço criativo, temos em nossa frente um : campo de investigação produtivo que começou a ser : explorado ao longo destas décadas. Porém, este é um : processo difícil de que trilha caminhos nem sempre : são claros e consistentes, principalmente dentro do : esporte, que é apenas uma das facetas deste imenso : universo que atua a criatividade.

Contudo estamos conscientes que, através do : embasamento científico proporcionado pelos vários : enfoques das diferentes correntes de estudo da : criatividade, será possível chegarmos a pontos : confluentes da criatividade dentro do esporte.

\section{4- REFERÊNCIAS BIBLIOGRÁFICAS:}

AMABILE, T.M. The social psychology of " creativity. New York: Springer. Verlag. 1983.

COSTA,V.T.;NOCE,F.;SAMULSKI, D. M. Análise dos : conceitos de criatividade e inteligência de jogo : de jogadores de voleibol de alto nível (Superliga : 97/98 Brasileira): Um estudo comparativo entre gêneros. SEMANA DE INICIAÇÃO CIENTIFICA DAUFMG ,9, 2000, Belo Horizonte. Resumos da IX Semana de Iniciação Científica da UFMG. Belo Horizonte: Imprensa Universitária, p.104,2000. CRUTCHFIELD, R.

Conformity and creative thinking. In: GRUBER, H.; TERRELL, G.; WERTHEIMER, M. (Eds). Contemporary approaches to creative thinking. New York: Atherton, 1962. p.120-140.

CSIKSZENTMIHALYI, M. Motivation and creativity: Toward a synthesis of structural and energistie approaches to cognition. New Ideas in Psychology, 6,1988a. p.159-176.

CSIKSZENTMIHALYI, M. Society, culture, and person: A system view of creativity. In: STERNBERG, R. (Ed). The nature ofcreativity. Cambridge University Press. 1988b. p. 325-339. CSIKSZENTMIHALYI, M. The domain of creativity. In: RUNCO, M.; ALBERT, R. (Eds). Theories of creativity. Newbury Park, CA Sage, 1990. p.190212. DE BONO, E. Lateral thinking for

\section{management.}

New York: McGraw-Hill,1971. DE BONO,

E. Six thinking hats. Boston: Lide,

Brouwn,1985. DE BONO, E. Serious

creativity: Using the power of lateral thinking to create new ideas. New York: HarperCollins, 1992. FELDMAN D.

H. Four frames for the study of creativity. Creativity Research Journal, 2:104111,1990. FELDHUSEN J. F.; \& GOH B.E. Assessing and

Accessing Creativity: An interpretive review of theory, research, and development. Creativity Research Journal, 8: 1995. p. 231-247.

FINKE, R. A; WARD, T.B; \& SMITH, S. M. Creative Cognition: Theory Research and applications. Cambridge, MA: MIT Press, 1992.

GARDNER, H. Creative lives and creative works: A synthetic scientific approach. In: STERNBERG, R. (ed) The nature ofcreativity. Cambridge: University Press, 1988. p.298-324. GARDNER, H. Frames of mind. New York: Basic, 1983/1993. GRECO, P. J. O Ensino do comportamento tático nos Jogos Esportivos: Aplicação no Handebol. 
(1) Campinas: Faculdade de Educação da UNICAMP, 1995 (Tese de doutoramento em Educação) GRECO,P.J.; COSTA,V.T.; NOCE, F.; et al. Análise : do nível de conhecimento tático: voleibol, " handebol, futsal. In: Resultado da Avaliação : dos Jogos da Juventude 1997. Brasília: INDESP, " p.81-102,1998.

GOLLAN, S. E. The creativity motive. Journal oj ' Personality, 30:1962. p.588-600,

GOUCH, H. G. A creativity scale for the adjective * check list. Journal of Personality and Social : Psychology, 37:1979.p. 1398-1405.

GUILFORD, J.P. Intelligence: 1965 modell. " American psychologist, 21: 1966.p.20-26.

HAMSEN, L \& SAMULSKI D. Análise qualitativa de processos criativos no Jutebolprofissional. " Probal: Heidelberg. 1999.

HENNESSEY B. A, \& AMABILE, T.M. The conditions of creativity. In: STERNBERG, R. (ed). Thenature : of creativity. Cambridge: University Press. : 1988.p. 11-38.

LUBART, T. I. Creativity and cross cultural variation. International Journal of Psychology, 25:1990.p. " 39-59.

MACKINNON, D. W. Personality and the realization of creative potential. American Psychologist. " 20:1965.p. 273-281

MADURO, R. Anistie creativity in a Brahmin : painter community. Research monograph 14, " Berkeley: Center for South and Southeast Ásia : Studies, University of Califórnia. 1976.

MAGILL, R. Aprendizagem motora: conceitos e " aplicações. São Paulo: Edgard Blücher, 1984

MORAES, LC.DDURAND-BUSH N.; SALMELAJ. H. " Modelos de desenvolvimento de talentos. In: SAMULSKI, D. M.(Ed). Novos Conceitos em " Treinamento Esportivo. Brasília : Indesp,1999 : p. 173-190.

OSBORN, A F. Applied imagination (Ed). New : York: Scribner's 1953.

PAULA P. Processo de Validação de teste para " avaliar a capacidade de decisão tática e o: conhecimento declarativo no voleibol. situações de ataque de rede. Belo Horizonte: Escola de Educação Física da UFMG, 2000.189 " p. (Dissertação de mestrado em Educação : Física/Treinamento Esportivo)
ROTH, K.; RAAB, M.; GRECO, P. O modelo da incubação incidental (MII): um estudo semiexperimental sobre o desenvolvimento da criatividade de jovens esportistas brasileiros e alemães. In: RELATÓRIO do projeto de intercâmbio de pesquisadores com a R.F.A. Apoio do programa PROBRAL convênio CAPESDAAD, 1998. ROTHENBERG, A. \&

HAUSMAN, CR. (Eds) The creativity question. Durham, NC: Duke University Press. 1976. SALMELA, J.H.

Learning from the development of expert coaches. Coaching and Sport Science Journal, n.2 v.2,1995.p.3-13. SCHMIDT R.

A . Aprendizagem e Performance Motora: dos princípios á prática. São Paulo: Movimento, 1993- 309 p. SILVER, H. R.

Calculations risks-. The socioeconomic foundations of aesthetic innovation in na Ashante carving community. Ethnology, n.20 v.2, 1981.p.101-114.

SIMONTON, D. K. Creativity, leadership, and chance. In: STERNBERG, R. (ed) The nature of creativity. Cambridge University Press. 1988. p.386426. STERNBERG, RJ. Intelligence Applied: Understanding and increasing your intellectualskills. San Diego: Harcourt; Brace, Jovanovich.1986. STERNBERG, R\& LUBART,

T. Investing in creativity.

American Psychologist, 51, 1996. p.677-688.

STERNBERG, RJ. LUBART T.I. The concept of creativity prospects and paradigms. In: STERNBERG, R. (Ed). Handbook of Creativity, cap 1, Melbourne, 1999 p.3-15.

TORRANCE, E. P. Torrance Tests of Creative Thinking. Lexington, MA: Personnel Press, 1974.

WEISBERG, R. W. Creativity, genius and other myths. New York: Freeman. 1986.

WEISBERG, R. W. Creativity: Beyond the myth of genius. New York: Freeman. 1993.

\section{NOTAS}

1. Coordenador do Laboratório de Psicologia do Esporte (LAPES-UFMG).sam@olimpic.eef. ufing. br 


\section{:}

2. Coordenador do Laboratório de Psicologia do : Esporte do UNILESTE-MG.

fnoce2000@yahoo.com.br

\section{ENDEREÇO PARA CONTATO}

3. Professor da Universidade de Itaúna - MG.

Av. Presidente Carlos Luz, 4664. B. Pampulha.

varley@cenesp.eef.ufmg.br

Belo Horizonte-MG CEP:31310-180. 